\section{Numerical Study of Savonius Wind Turbine Rotor with Elliptic Angle Shape Variation}

\author{
Antonius Hadi Sudono Putranto, Vivien S. Djanali Bambang Arip Dwiyantoro \\ Department of Mechanical Engineering, Institut Teknologi Sepuluh Nopember, Surabaya 60111, Indonesia \\ Received: 4 July 2019, Revised: 1 September 2019, Accepted: 10 September 2019
}

\begin{abstract}
The Savonius wind turbine uses a half-cylinder blade which is often called a bucket assembled so that the cross-section forms an "S". This turbine is seen in the form of a half-cylinder consisting of a concave side and a convex side. This turbine is one type of Vertical Axis Wind Turbine (VAWT) that uses the difference in drag forces between the two buckets to be able to rotate the rotor. Therefore this rotor has the ability to self-start, which other wind turbines do not have, even so, the performance of the turbine. Savonius wind is still relatively low, so that it cannot be applied until now. Many studies have been carried out to improve performance, some of which include adding shielding, end plates, changing the shape of the blades, gap overlap, and others. The analysis in this numerical study included a comparison of the performance of conventional Savonius wind turbines and elliptic Savonius wind turbines with an assumed steady flow 2D flow and using turbulent viscous transitions $\mathrm{k}-\mathrm{k}_{L}-\omega$ and $\mathrm{k}-\omega$ SST with variations in flow velocity and angle of incidence of flow to the position of the rotor of the Savonius turbine. This results evaluated were the static torque coefficient with respect to the rotor position, the pressure distribution along the blade surface, and the wind flow characteristics near the rotor. The results of this study indicated that the modified wind turbine rotor had a higher static torque coefficient at low speeds. The two types of turbine rotors had relatively the same self-starting capability at high speeds.
\end{abstract}

Keywords: Turbine, elliptic blade, numerical, Savonius, static torque coefficient

\section{Introduction}

Wind turbines with a vertical axis, such as the Savonius turbine, have a semi-cylindrical bucket shape that is mounted in the opposite direction. This turbine makes use of the drag force acting on the blades to get torque. This process produces rotation with a certain angular speed. This turbine will produce greater power with increasing torque. Savonius turbines generally have a large starting torque and can run at relatively low speeds. The initial design of the Savonius turbine had a disadvantage, namely its relatively low efficiency. Research to increase the efficiency of the Savonius wind turbine can be carried out.

The Savonius turbine has the potential to be developed because this turbine produces large amounts of torque at low rotation speeds and is cheap to manufacture [1]. It can also used as a hybrid turbine such as in [2]. Modifications in an effort to improve the performance of the Savonius wind turbine have been made in the form of adding endplates, shielding, variations in bucket shapes, number of blades and stages, variations in aspect ratio, gap overlap and spacing, and others that have been shown to increase turbine performance because they have a direct impact on improving the coefficient of power and torque produced [3].

\footnotetext{
”Corresponding author. Email : vivien_s@me.its.ac.id
}

Basically, one of the advantages of the Savonius vertical axis wind turbine is that it is self-starting. The initial torque of the Savonius turbine itself is quite good compared to other vertical axis wind turbines. The torque itself can still be developed because it is considered inadequate due to the negative torque on the returning blade [4]. Therefore, research to minimize the negative torque was carried out. Research from [4] also examined the rotor performance of standard Savonius wind turbines without and with obstacles.

One of the studies to improve the self-starting ability by changing the shape of the blade was carried out by [5]. The performance of the elliptic blade shape was investigated with the obstacle compared to the standard Savonius wind turbine rotor shape. His research resulted that wind turbine rotors with elliptic blades with obstacles have better performance than standard Savonius wind turbine rotors with obstacles. The wind turbine rotor with an obstacle is considered less applicable to outdoor conditions, which are becoming the boundary conditions, because in outdoor conditions the air can come from any direction while the use of an obstacle is only effective if the air comes in one direction towards the obstacle that will flow to the advancing blade. So this research will examine the blade shape designed by Mohamed [5] without 
obstacle to suit wind at any directions.

Further studies were conducted on the modification of the profile blades of the rotor. Modi et al. [6] used Bach-profile blade rotor in an irrigation system. Simulation results showed that Bach-profile blade had better performance compared to the standard Savonius blade [7]. A comparison between the Bach-profile and Benesh-profile was studied [8]. Another study improved the self-starting capability of the Bach-profile blade with flaps [9]. Other designs of blade profile have also been proposed [10-12].

Kacprzak et al. [13] studied the performance comparison between three types of turbine blades, namely the standard Savonius wind turbine rotor, Bach type rotor, and rotor with the elliptic blade. It is found that the Bach-type rotor has the best power coefficient and the standard Savonius wind turbine rotor has the lowest power coefficient. The simulation dimensions and domains in the study were not detailed and the torsion graph trend towards the rotor position is different from other studies.

Based on previous studies, motivation emerged to research wind turbines to help complete existing information with valid data to know the interaction and characteristics of the wind flowing through the modified wind turbine rotor and standard Savonius turbine rotor and providing performance data in the form of the static torque coefficient with respect to the rotor position and the graph of the pressure distribution along the blade of the Savonius turbine that has been modified and standardized. In this research, a numerical study uses a two-dimensional model. The Savonius turbine studied uses standard and elliptic blades with two blades. The results of this study obtained the graph of the moment coefficient with respect to the rotor angle and the graph of the distribution of the pressure coefficient along the blade surface so that it can be determined which of the two variations of the turbine capable of extracting the most optimal wind energy.

\section{Method}

Two-dimensional, steady simulations were performed using ANSYS FLUENT. This study uses domains and boundary conditions with dimensions as shown in Figure 1

The standard and modified Savonius wind turbine rotor geometry is shown in Figure 2, The elliptic rotor geometry configuration is based on research by [5]. The two rotors have the same diameter $(D)$.

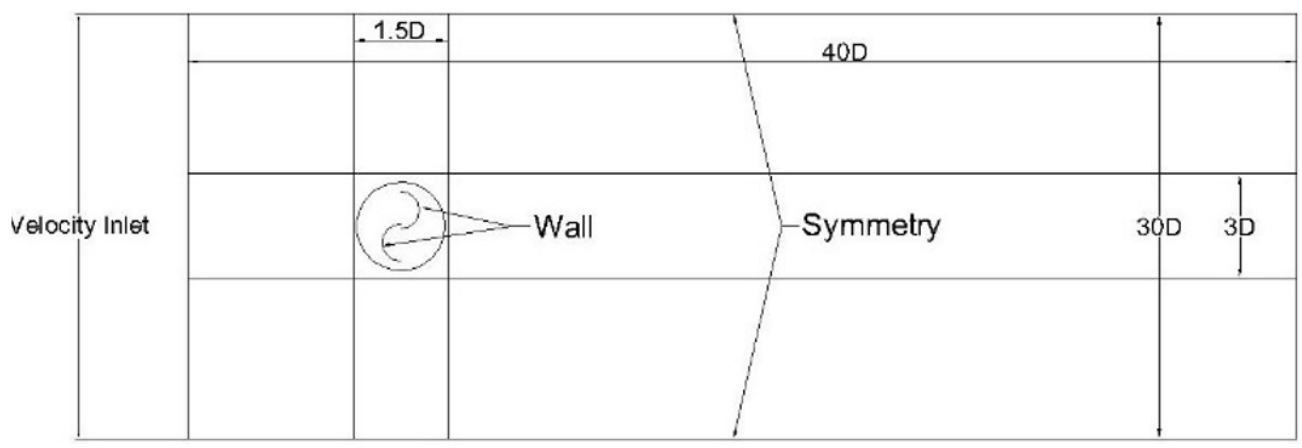

Figure 1. Domain and boundary conditions of the simulation.

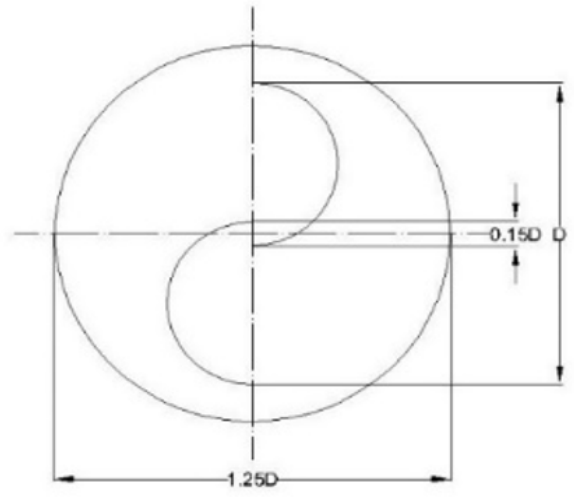

(a)

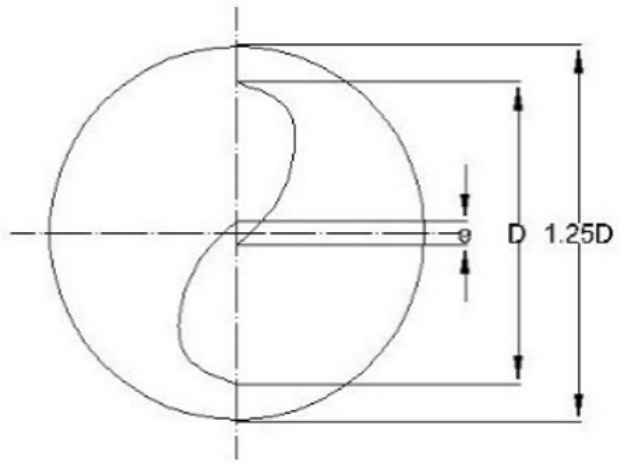

(b)

Figure 2. Rotor geometry: (a) standard blade, (b) elliptic blade. 
The study of the two types of rotors was simulated using the same domain. The turbulence model tested in this study were the viscous transition model of $\mathrm{k}-\mathrm{k}_{L}-\omega$ and $k-\omega$ SST for one rotor position. Table 1 shows the parameter and variation of the tests to be carried out. The test will be carried out with the rotor considered to be a rigid body and in a static state. For comparison of the two viscous models, it is sufficient to analyze one rotor position, namely the rotor angle $\theta=90^{\circ}$. The simulations were run in second order discetization scheme for pressure, momentum and turbulence equations. The simulation domain was discretized with a total number of cell of 484,761. Grid independency test was performed and it is found out that further refining the mesh resulted only of $1 \%$ difference. Inflation mesh around the blade profile was used to ensure the near wall $\mathrm{y}^{+}$value is close to unity. The mesh used is shown in Figure 2, The boundary conditions used were the velocity inlet boundary condition; the upper and lower limits used the symmetry, the blade used the wall and the outlet will be determined using the outflow. A pressure outlet at 0 Pascal (gage) was considered because the pressure acting on the outlet is at atmospheric pressure. The simulation results were extracted in the form of qualitative and quantitative data. Qualitative data is in the form of flow visualization by displaying the flow pattern across the rotor blade. The quantitative data is a graph of the static torque coefficient to the rotor angle and the distribution of the pressure coefficient along the blade.

Table 1. Simulation modeling parameters.

\begin{tabular}{|c|c|}
\hline Turbulence model & Turbulent k- $\omega$ SST (for the rotor position ), $\mathrm{k}-\mathrm{k}_{L}-\omega$ transition \\
\hline Rotor diameter & $32 \mathrm{~cm}$ \\
\hline Wind speed & $4,7,10(\mathrm{~m} / \mathrm{s})$ \\
\hline Rotor type & Standard Savonius, Elliptic \\
\hline Rotor position & $30^{\circ}, 90^{\circ}, 150^{\circ}$ \\
\hline
\end{tabular}

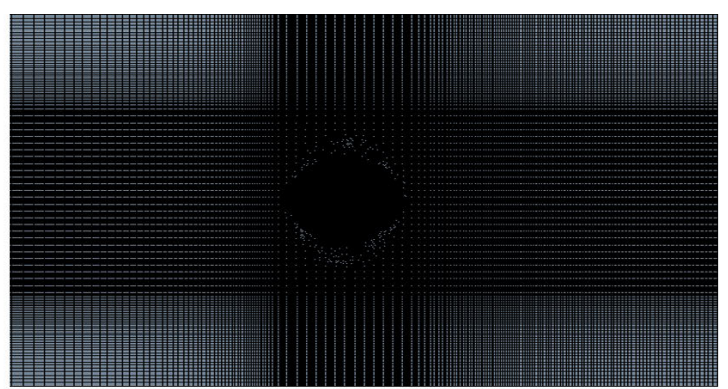

(a)

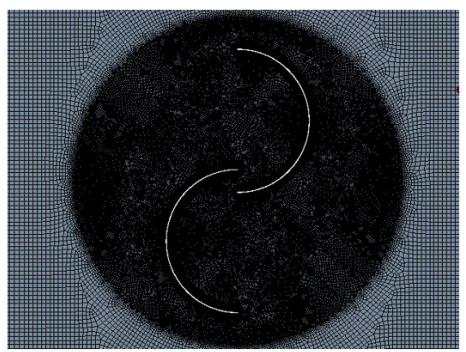

(b)

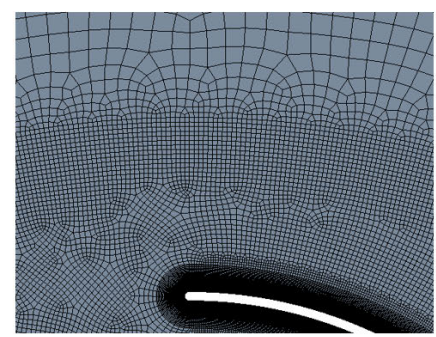

(c)

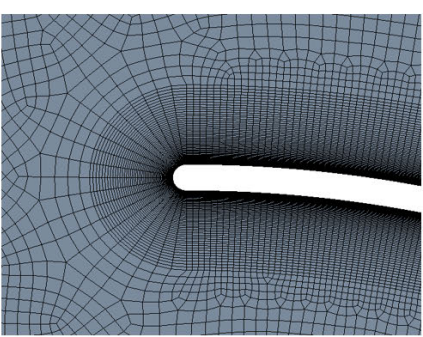

(d)

Figure 3. Meshing: (a) distant view, (b) rotor view, (c) circular domain edge view, (d) boundary layer. 


\section{Results and Discussion}

\subsection{Comparison of the Turbulence Model}

To get the appropriate results, the turbulence intensity was calculated based on the Reynolds number and using a length scale of $D$, the turbulent intensity was obtained as in Table 2 .

Table 3 shows the comparison between the two simulated turbulence models with the standard Savonius wind turbine model with angle $\theta=90^{\circ}$, These two models were compared with the experimental results [4], where they got a torque result of $0.75 \mathrm{Nm}$ for the standard Savonius turbine model at angle $\theta=90^{\circ}$ with a wind speed of $7 \mathrm{~m} / \mathrm{s}$. The comparison between this experiment and the turbulence model of the $\mathrm{k}-\mathrm{k}_{L}-\omega$ transition model is shown with an error of $2.7 \%$, while the k- $\omega$ SST model is shown with an error of $8.7 \%$. From these results, the turbulence model used for all variations is a $\mathrm{k}-\mathrm{k}_{L}-\omega$ transition model. At other velocities, the difference between the turbulence transition model $\mathrm{k}-\mathrm{k}_{L}-\omega$ and $\mathrm{k}-\omega \mathrm{SST}$ is shown in the difference column.

3.2. Comparison of Standard and Modified Savonius Rotors at Velocity of $4 \mathrm{~m} / \mathrm{s}$

Simulation analysis at a speed of $4 \mathrm{~m} / \mathrm{s}$ was carried out by comparing the two types of rotors at each angle. Figure 4 shows the pathline streamline and speed contours of the Savonius wind turbine at various angles with a wind speed of $4 \mathrm{~m} / \mathrm{s}$. At an angle of $\theta=30^{\circ}$, the standard Savonius wind turbine had a wake that was relatively the same as the modified form. In the convex advancing blade, separation occured, which results in a small wake due to the far separation from the blade tip. In the concave side of advancing blade, the flow flows to the overlap. At an angle $\theta=90^{\circ}$ the downstream area of the turbine rotor had unsteady flow in the wake form. So that the flow phenomenon when interacting with the rotor and downstream areas cannot be captured accurately, quantitative data in the form of a pressure coefficient distribution is needed. At the angle $\theta=150^{\circ}$, in general, the blockage area formed in the downstream area was bigger than the angle $\theta=30^{\circ}$ and $\theta=90^{\circ}$. In the concave side of advancing blade (standard form), wake occurred, which will reduce the drag force received by the advancing blade. This did not happen in the modification advancing blade. The wake in the concave side will have an impact on the decrease in momentum from the standard rotor. It can also be seen that these two types of rotors cause the overlap jet phenomenon. The flow velocity as it passes through the overlap area increased dramatically. The speed increase also occurred in the blade tip of the advancing blade. The low speed occurred mostly in the concave side of advancing blade and the downstream area of the rotor, which was generated by the wake.

Figure 5 describes the flow phenomenon on the blade surface in the form of the pressure coefficient distribution. At the angle $\theta=30^{\circ}$ there was a difference in pressure between the advancing blade and the returning blade on the concave side of advancing blade. In the convex or downstream advancing blade, there was a separation that is not too close to the blade tip causing a small wake which causes the pressure to drop to negative in the convex advancing blade until it reaches the blade tip near the center of rotation. The pressure drop was also experienced by the overlap area, where the pressure drops to a negative effect due to the phenomenon of overlap jets where the speed increased drastically. The same phenomenon occurred in the returning blade section, where the downstream and overlap pressure dropped to negative. The difference of pressure between the concave and convex surface of the blade was greater in the modified blade, particularly for the advancing blade. This suggested that the drag force generated in the advancing side of the modified blade is greater than that of the standard blade, and thus the positive torque generated was higher.

Table 2. Turbulent intensity used in the simulation.

\begin{tabular}{|c|c|c|}
\hline Wind speed (m/s) & Reynolds Number & Turbulent Intensity \\
\hline 4 & $87,627.14$ & $3.85 \%$ \\
\hline 7 & $153,347.50$ & $3.59 \%$ \\
\hline 10 & $219,067.80$ & $3.43 \%$ \\
\hline
\end{tabular}

Table 3. The resulting torque using two different turbulence models.

\begin{tabular}{|c|c|c|c|}
\hline \multirow{2}{*}{ Wind speed (m/s) } & \multicolumn{2}{|c|}{ Torque (N.m) } & \multirow{2}{*}{ Difference (\%) } \\
\cline { 2 - 4 } & $\mathrm{k}-\mathrm{kL}-\omega$ transition & $\mathrm{k}-\omega$ SST & \\
\hline 4 & 0.253 & 0.388 & 34.865 \\
\hline 7 & 0.735 & 0.823 & 10.694 \\
\hline 10 & 1.562 & 2.058 & 24.105 \\
\hline
\end{tabular}



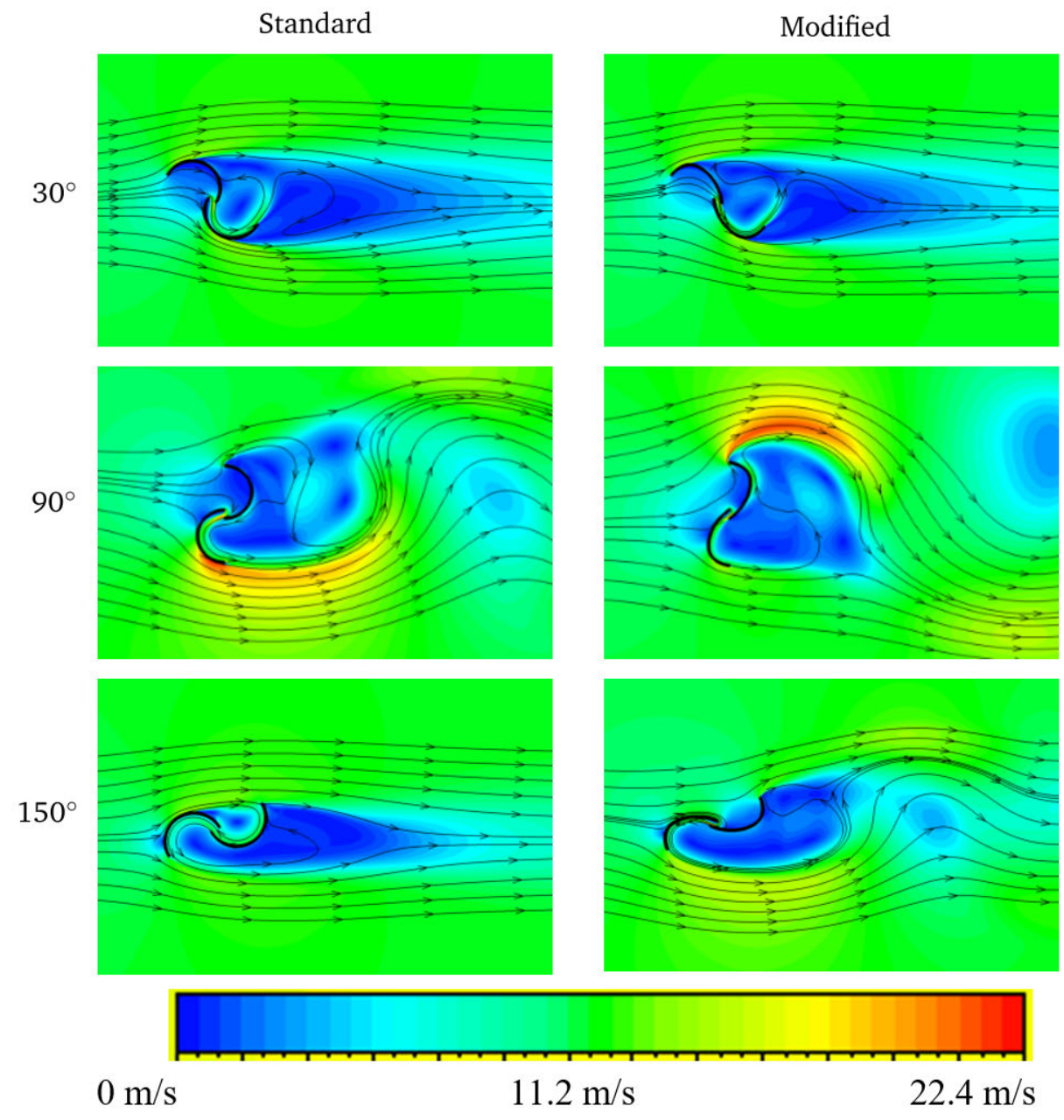

Figure 4. Wind turbine velocity pathline at for freestream velocity of $4 \mathrm{~m} / \mathrm{s}$.

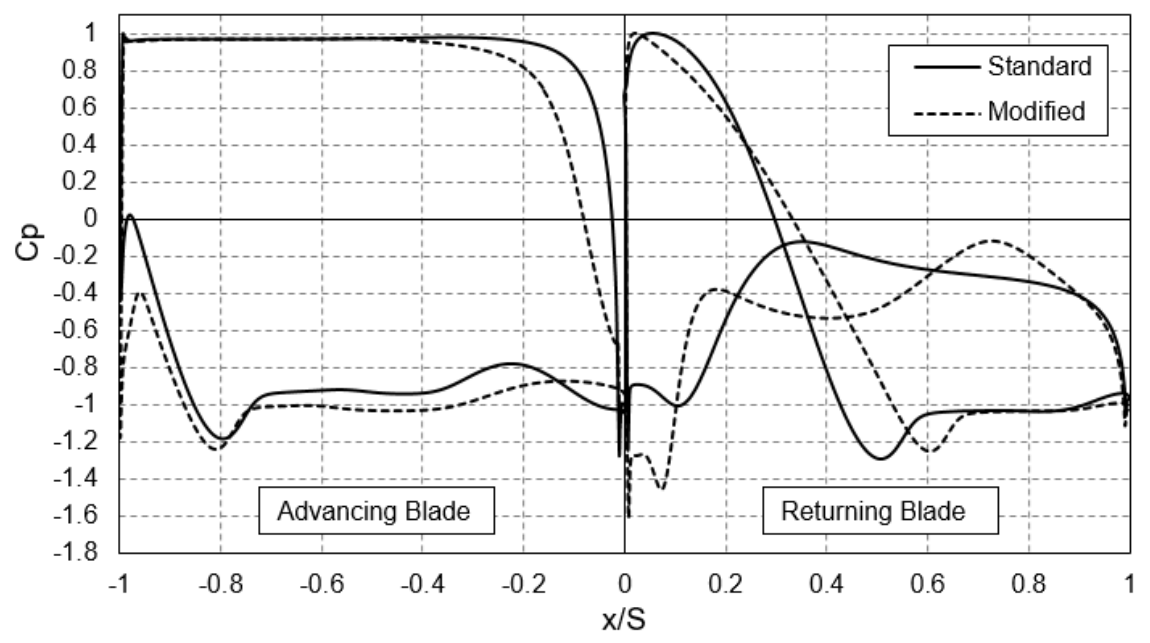

Figure 5. Pressure coefficient distribution along the blade surface for velocity of $4 \mathrm{~m} / \mathrm{s}$ at rotor angle of $30^{\circ}$.

In Figure 6, when the rotor angle $\theta=90^{\circ}$, there was a stagnation point on the advancing blade tip so that the pressure on the advancing blade was divided into two areas, the concave side had high pressure, and the convex side had low pressure. Both of these parts will experience a pressure drop. In the concave side, the pressure drop will occur when the flow enters the overlap area. In the convex part, the pressure drop occurred along the convex 
surface due to a decrease in speed followed by separation, which will cause a wake. For the returning blade section, the highest pressure was generated at the stagnation point right in the middle of the returning blade area and was divided into two regions. The flow towards the $+y$-direction maintained this high pressure because it also contributed to the pressure from the high pressure created by the advancing blade and then flow through the overlap experiencing a pressure drop. Those in the $-y$-direction experienced a pressure drop down to the blade tip. At an angle $\theta=90^{\circ}$, the pressure drop created by the overlap jet phenomenon made the pressure difference at the concave side smaller than the pressure difference in the convex part, which was directly divided into two regions. This overlapping effect also lowered the pressure and causes a wake in the downstream part. The two rotor shapes had a similar trend, but it can be seen that the modified rotor forms produced a greater difference in pressure in the upstream and downstream sections of the advancing blade than the standard form. This indicates that the shape of the modified rotor produces greater pressure.

In Figure 7, when the rotor angle $\theta=150^{\circ}$, it is seen in the graph that in general, the modified rotor form produced a greater pressure than the standard form. The phenomenon that occurred when the angle $\theta=150^{\circ}$ resembles the angle $\theta=30^{\circ}$ and $\theta=90^{\circ}$ where the concave side of advancing blade had a large pressure then decreases in the overlap section, and the convex side experienced a decrease in pressure due to a wake, while the returning section, the blade pressure drops due to separation in the flow towards $-y$-direction and on the overlap.

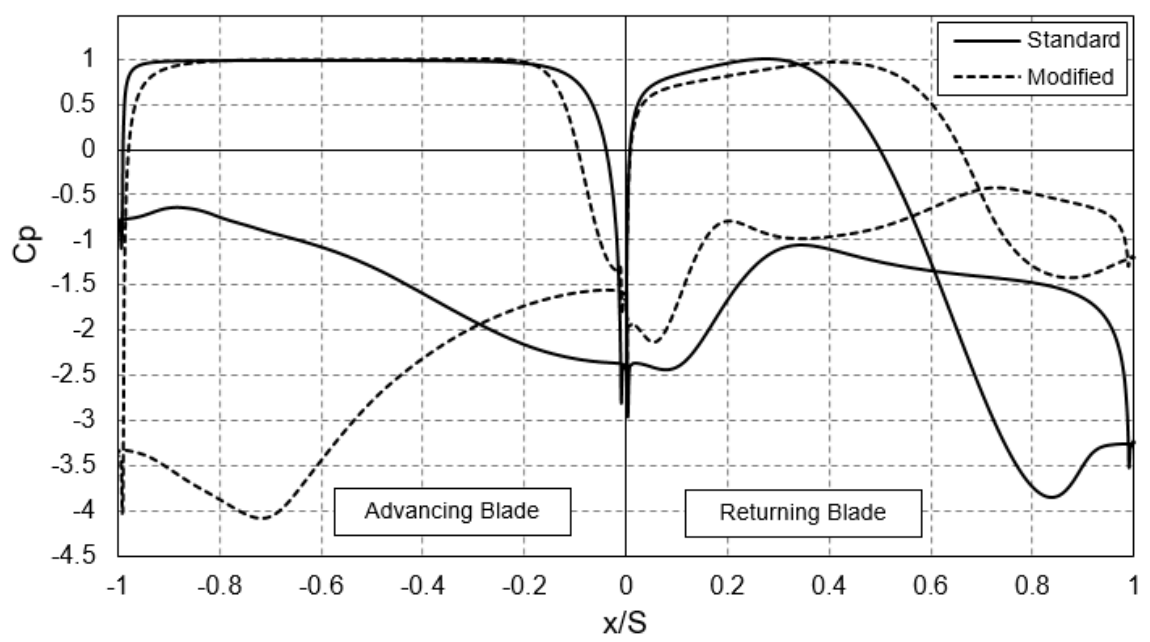

Figure 6. Pressure coefficient distribution along the blade surface for velocity of $4 \mathrm{~m} / \mathrm{s}$ at rotor angle of $90^{\circ}$.

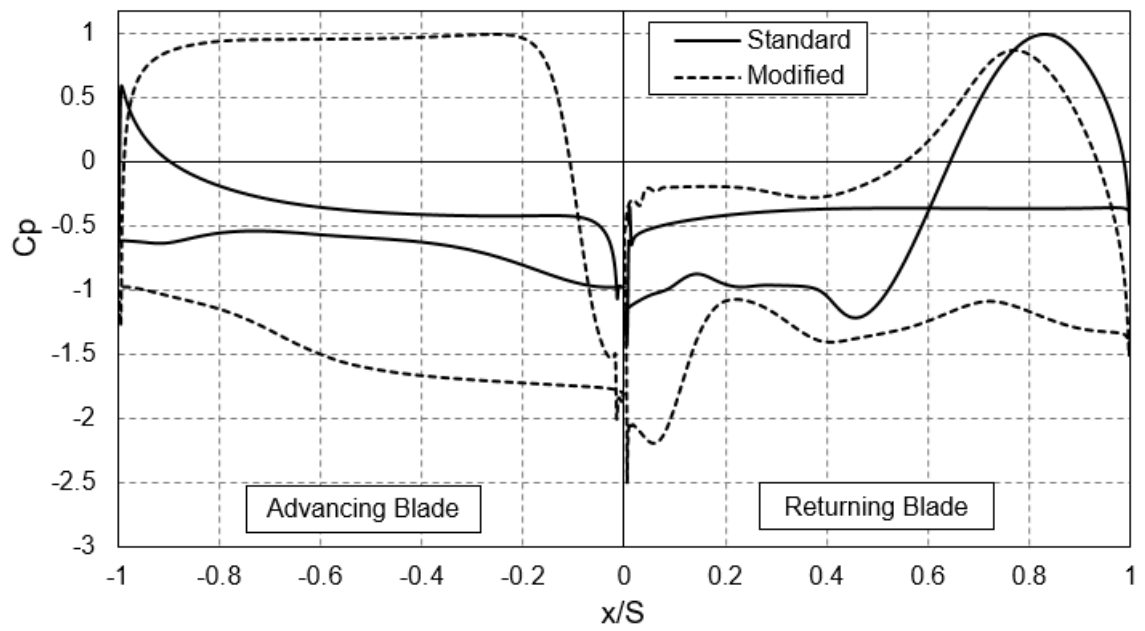

Figure 7. Pressure coefficient distribution along the blade surface for velocity of $4 \mathrm{~m} / \mathrm{s}$ at rotor angle of $150^{\circ}$. 
Figure 8 shows the static torque coefficient that occurs at each corner of the Savonius wind turbine. In Figure 8, it can be seen that the highest static torque coefficient for the standard form Savonius wind turbine was when the angle $\theta=30^{\circ}$. It can be seen in the picture that the phenomenon that occurs was at an angle $\theta=30^{\circ}$. The torque value produced by the modified form was slightly higher, with a difference of $4.2 \%$. At an angle $\theta=90^{\circ}$, the torque difference between the modified rotor and the standard rotor becomes large, with a difference of $11 \%$. After the angle $\theta=90^{\circ}$, the torque value of the modified form decreased until it became lower than the standard form. At the angle $\theta=150^{\circ}$, the effect of the overlap jet on the modified rotor was not functioning properly. All the torque from the three variations of the angle was positive because the shape of the blade creates a pressure difference in the upstream and downstream parts, making the rotor rotate clockwise. The overlap reduced the negative torque generated and the direction of the drag force was still in the same direction as the turbine rotation.

3.3. Comparison for Speed Variations of $7 \mathrm{~m} / \mathrm{s}$ and $10 \mathrm{~m} / \mathrm{s}$ at the angle $\theta=150^{\circ}$

Figure 9 shows a comparison of the torque values between standard Savonius turbine rotors and modified rotors. In general, the trend in the torque coefficient graph for wind speeds of $7 \mathrm{~m} / \mathrm{s}$ and $10 \mathrm{~m} / \mathrm{s}$ had a different trend from $4 \mathrm{~m} / \mathrm{s}$ where when the rotor was angled $\theta=150^{\circ}$ the rotor of the standard Savonius wind turbine had greater torque than the modified rotor. This phenomenon indicates that the modified rotor form gives a greater negative torque when the rotor angle $\theta=150^{\circ}$. It can be seen that at a speed of $7 \mathrm{~m} / \mathrm{s}$ the difference in the value of the static torque coefficient at an angle of $\theta=150^{\circ}$ is 0.341 and at a speed of $10 \mathrm{~m} / \mathrm{s}$ was 1.961 .

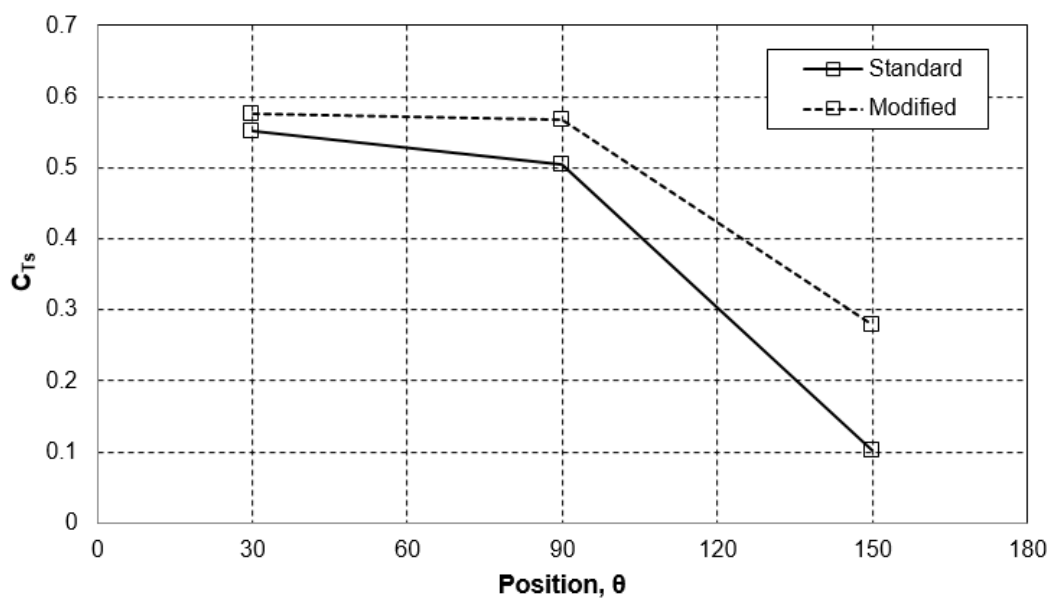

Figure 8. Graph of static torque coefficient to rotor angle for velocity $4 \mathrm{~m} / \mathrm{s}$.

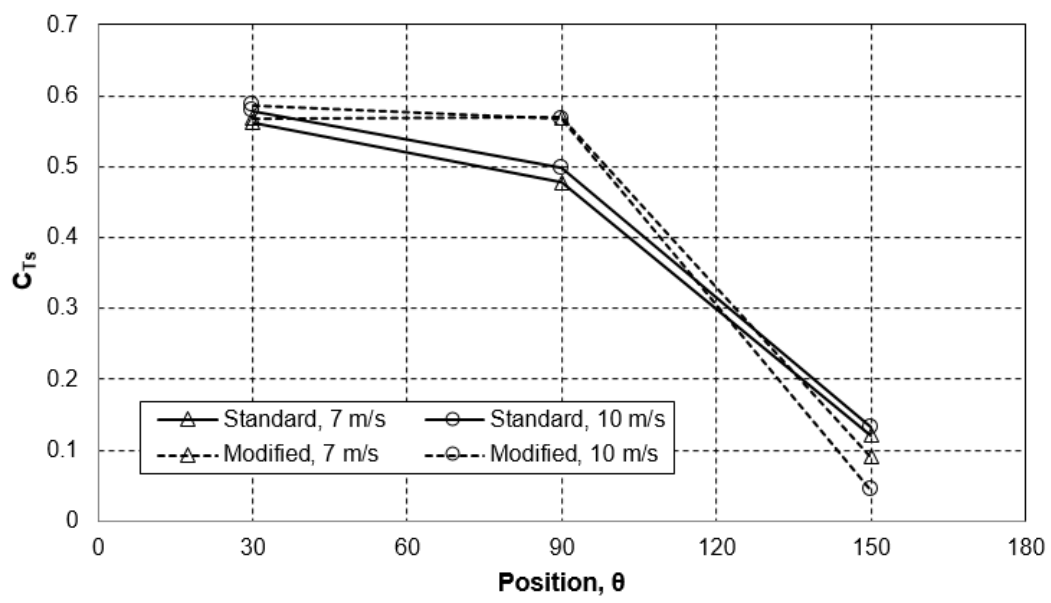

Figure 9. Graph of static torque coefficient for velocity of $7 \mathrm{~m} / \mathrm{s}$ and $10 \mathrm{~m} / \mathrm{s}$. 
Figure 10 shows that in general, the two types of rotors at speeds of $7 \mathrm{~m} / \mathrm{s}$ and $10 \mathrm{~m} / \mathrm{s}$ produced the same trend of the pressure coefficient graphs. At an angle of $\theta=150^{\circ}$ the modified rotor produced greater pressure than the standard Savonius wind turbine rotor. It can also be seen that at an angle $\theta=150^{\circ}$ of the modified wind turbine rotor, the maximum pressure generated by the returning blade was greater than the advancing blade. This phenomenon did not occur at a wind speed of $4 \mathrm{~m} / \mathrm{s}$. Both types of rotors experienced a decrease in pressure in the overlap area where the returning blade minimum pressure was lower than the advancing blade. In the modified rotor, it can be seen that the advancing blade produces an area that represents positive torque, and the returning blade represents negative torque. At a wind speed of $7 \mathrm{~m} / \mathrm{s}$ and $10 \mathrm{~m} / \mathrm{s}$, the modified rotor returning blade produced a large negative torque and produced a maximum pressure greater than the advancing blade, thus reducing the positive torque generated. In standard Savonius rotors, the advancing blade produced positive torque because the concave side produces higher pressure than the convex side. The standard returning blade provided an area from the difference in pressure coefficient from the inner bladetip (blade tip near the center of rotation) to a value of $\mathrm{x} / \mathrm{S}=0.6$, which results in positive torque, thus increasing the positive torque value. This causes the torque produced by the standard Savonius turbine rotor was higher than the modified turbine rotor.

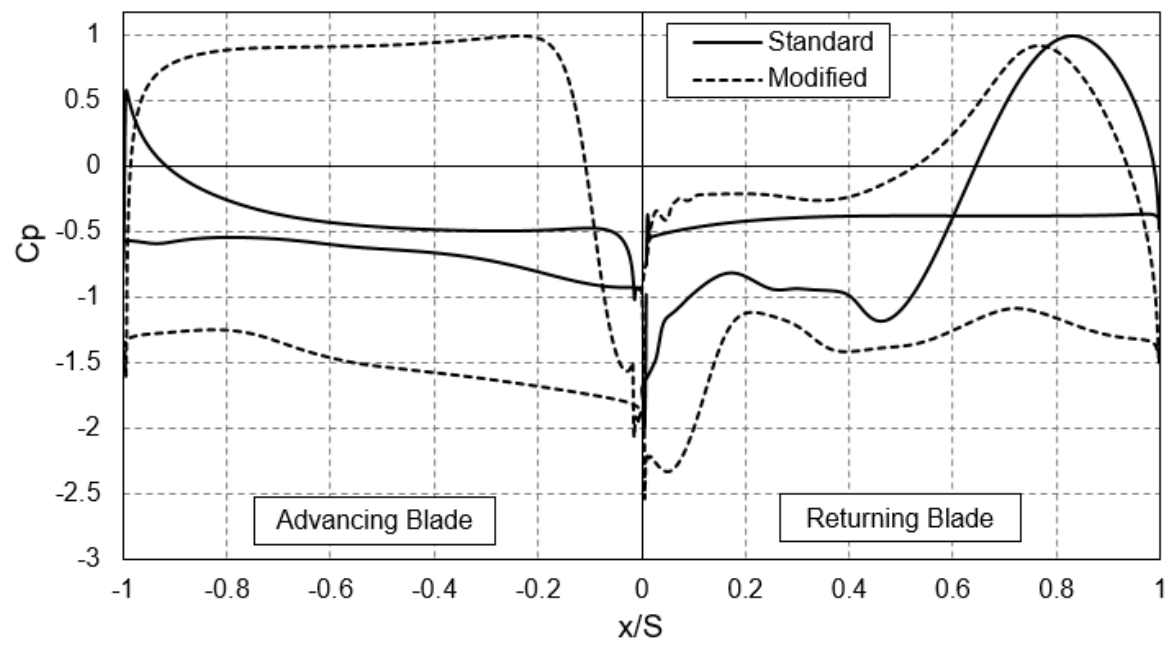

(a)

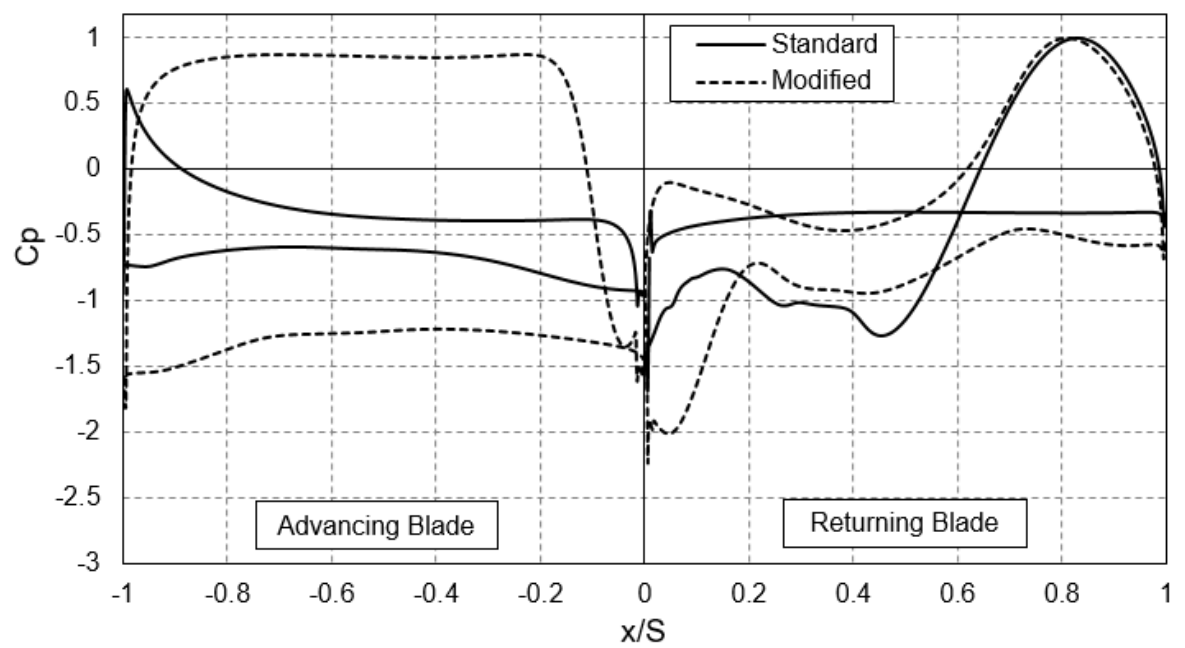

(b)

Figure 10. The pressure distribution along the blade at an angle $\theta=150^{\circ}$ (a) velocity of $7 \mathrm{~m} / \mathrm{s}$ and (b) velocity of $10 \mathrm{~m} / \mathrm{s}$. 


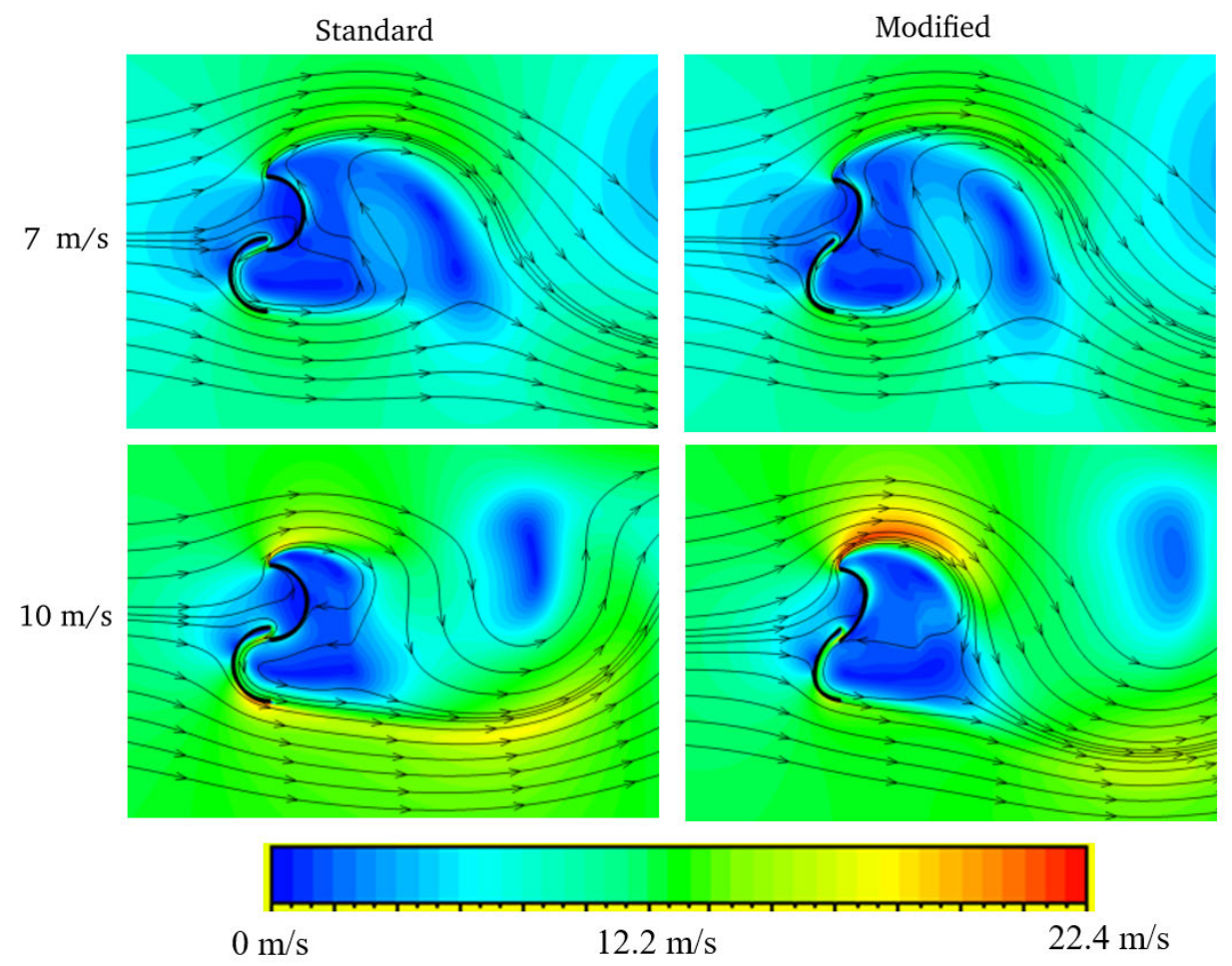

Figure 11. Pathline and velocity contour at angle $\theta=90^{\circ}$.

3.4. Comparison for Speed Variations of $7 \mathrm{~m} / \mathrm{s}$ and $10 \mathrm{~m} / \mathrm{s}$ at an angle of $\theta=90^{\circ}$

Figure 11 shows the flow pathline at an angle of $\theta=90^{\circ}$ at a wind speed of $7 \mathrm{~m} / \mathrm{s}$ and $10 \mathrm{~m} / \mathrm{s}$. At a speed of $7 \mathrm{~m} / \mathrm{s}$, the flow characteristics in the two types of rotors were almost the same, wherein the standard rotor, pathline at a speed of $7 \mathrm{~m} / \mathrm{s}$ had different flow characteristics with a speed of $4 \mathrm{~m} / \mathrm{s}$ because the flow in the downstream rotor at an angle of $\theta=90^{\circ}$ had the ever-changing unsteady characteristics. At a wind speed of $7 \mathrm{~m} / \mathrm{s}$ the flow formed a separation on the blade tip of the advancing blade so that a wake occurred in the downstream part. At a speed of $10 \mathrm{~m} / \mathrm{s}$, it can be seen that the flow characteristics formed in the downstream section were different from the speed of $7 \mathrm{~m} / \mathrm{s}$. It can be seen in the speed contour around the rotor, the flow characteristics on the surface of the modified turbine rotor produced the same trend between speeds of $7 \mathrm{~m} / \mathrm{s}$ and $10 \mathrm{~m} / \mathrm{s}$, while in the standard Savonius turbine rotors, there were differences in color contours at wind speeds of $7 \mathrm{~m} / \mathrm{s}$ and $10 \mathrm{~m} / \mathrm{s}$ on the convex surface of the advancing blade. In general, it can be seen that the wake formed in the downstream is relatively the same at each speed.

\section{Conclusion}

In the standard form and a modified form of the Savonius wind turbine simulation with variations in wind speed of 4,7 , and $10 \mathrm{~m} / \mathrm{s}$, it can be concluded that flow interactions that occurred at an angle $\theta=30^{\circ}$ tend to produce a small wake resulting in the highest torque. At an angle $\theta=90^{\circ}$ the downstream flow was unsteady so that the flow characteristics produced a large enough wake in the downstream of the advancing blade or downstream of the returning blade. Angle $\theta=150^{\circ}$ produced the greatest negative torque resulting in minimum torque. The shape of the blade has an influence on the resulting torque. The maximum torque for the standard and modified Savonius wind turbines occurred at a wind speed of $10 \mathrm{~m} / \mathrm{s}$. This was because by changing the wind speed, the flow characteristics and pressure distribution on the rotor also changed and resulted in differences in the value of torque that works on the Savonius wind turbine blades. In general, it can be said that the modified form rotor has a torque that increased with increasing speed, but there were positions where the torque was very small, therefore it can be said that the modified form turbine rotor is more suitable in areas with low wind speeds. Both types of rotors had relatively the same self-starting capability.

\section{References}

[1] U. Saha and D. Maity, "Optimum design configuration of Savonius rotor through wind tunnel experiments," Journal of Wind Engineering and Industrial Aerodynamics, vol. 96, no. 8, pp. 1359-1375, 2008.

[2] B. A. Dwiyantoro and V. Suphandani, "The system design and performance test of hybrid vertical axis wind turbine," in AIP Conference Proceedings, vol. 1831, p. 020030, AIP Publishing LLC, 2017. 
[3] J. Akwa, H. Vielmo, and A. Petry, "A review on the performance of Savonius wind turbines," Renewable and sustainable energy reviews, vol. 16, pp. 3054 3064, 2012.

[4] B. D. Altan and M. Atılgan, "An experimental and numerical study on the improvement of the performance of Savonius wind rotor," Energy Conversion and Management, vol. 49, pp. 3425-3432, 2008.

[5] M. Mohamed, G. Janiga, E. Pap, and D. Thévenin, "Optimal blade shape of a modified Savonius turbine using an obstacle shielding the returning blade," Energy Conversion and Management, vol. 52, pp. 236242, 2011.

[6] V. Modi, N. Roth, and M. Fernando, "Optimumconfiguration studies and prototype design of a windenergy-operated irrigation system," Journal of Wind Engineering and Industrial Aerodynamics, vol. 16, no. 1, pp. 85-96, 1984.

[7] T. Zhou and D. Rempfer, "Numerical study of detailed flow field and performance of Savonius wind turbines," Renewable Energy, vol. 51, pp. 373-381, 2013.

[8] N. Alom, B. Borah, and U. K. Saha, "An insight into the drag and lift characteristics of modified Bach and Benesh profiles of Savonius rotor," Energy Procedia, vol. 144, pp. 50-56, 2018. Special Issue of the Fourth International Symposium on Hydrogen Energy, Renewable Energy and Materials, 2018 (HEREM 2018).

[9] S. Tabassum and S. Probert, "Vertical-axis wind turbine: A modified design," Applied Energy, vol. 28, no. 1, pp. 59-67, 1987.

[10] Z. Driss, O. Mlayeh, S. Driss, D. Driss, M. Maaloul, and M. S. Abid, "Study of the bucket design effect on the turbulent flow around unconventional Savonius wind rotors," Energy, vol. 89, pp. 708-729, 2015.

[11] M. Tartuferi, V. D’Alessandro, S. Montelpare, and R. Ricci, "Enhancement of Savonius wind rotor aerodynamic performance: a computational study of new blade shapes and curtain systems," Energy, vol. 79, pp. 371-384, 2015.

[12] W. Tian, Z. Mao, B. Zhang, and Y. Li, "Shape optimization of a Savonius wind rotor with different convex and concave sides," Renewable Energy, vol. 117, pp. 287-299, 2018.

[13] K. Kacprzak, G. Liskiewicz, and K. Sobczak, "Numerical investigation of conventional and modified Savonius wind turbines," Journal of Renewable energy, vol. 60, pp. 578-585, 2013. 